\title{
Discordância entre testes sorológicos para sífilis em pacientes HIV-positivos: perda de anticorpos treponêmicos?
}

\author{
Discrepancy between serological tests for syphilis in HIV-positive patients: absence of treponemal \\ antibodies?
}

\author{
Michel F.S. Fonseca \\ Maria L. Silva ${ }^{2}$ \\ Suzane P.F. Neves ${ }^{3}$
}

As doenças sexualmente transmissíveis constituem um grande problema de saúde pública em todos os países. A relação entre a sífilis e a infecção pelo HIV é bem conhecida. O próprio comportamento sexual de risco é fator para a aquisição da doença, bem como para a infecção pelo HIV. Também as ulcerações genitais causadas pela sífilis ou outras DSTs, levando à ruptura das barreiras mucosas, predispõem à infecção pelo HIV. A prevalência desta doença é maior em pacientes homossexuais HIV-positivos, quando comparados com homossexuais HIV-negativos. Além disto, muitos estudos mostram um curso clínico mais rápido e agressivo em pacientes co-infectados, podendo a doença evoluir mais precocemente e, em maior percentual, para o acometimento do sistema nervoso central (SNC), além de maior falha no tratamento ou recaída da infecção. Outro aspecto relevante são as alterações em testes sorológicos para sífilis, relacionados tanto à sororeativação (por ativação policlonal inespecífica de linfócitos induzida pelo HIV) quanto à soro-reversão (por falha na produção dos anticorpos antitreponêmicos devido ao comprometimento progressivo da função imune). Neste estudo, realizado entre janeiro de 1998 e abril de 2000, avaliamos os resultados dos testes sorológicos para sífilis de 90 pacientes HIV-positivos atendidos no Ambulatório de Doenças InfectoParasitárias (CTR-DIP) do Hospital das Clínicas da Universidade Federal de Minas Gerais (UFMG), cujas amostras foram processadas no setor de soro-imunologia do Laboratório Central desta instituição. Todas as amostras positivas para o VDRL foram confirmadas com um teste treponêmico, a hemaglutinação indireta (HAl). Deste total, 12 pacientes apresentaram HAI negativa (13,3\%). Uma vez que dados da literatura mostram que $1,7 \%$ dos resultados de VDRL é falsopositivo em pacientes infectados pelo HIV, o grande percentual de discordância entre o VDRL e a hemaglutinação observado neste estudo alerta para a possibilidade de perda de anticorpos antitreponêmicos no decorrer da infecção pelo vírus. Além disto, 11 dos 12 pacientes que apresentaram HAI negativa mostravam VDRL menor ou igual a $1 / 32$, sendo que este é, segundo alguns autores, um dos fatores de risco associado à perda de anticorpos antitreponêmicos ao longo da infecção pelo HIV. Desta forma, deve-se avaliar com cautela um resultado treponêmico negativo sempre que houver evidência de infecção sifilítica prévia ou atual.

\section{Referências}

I. Janier, M. et al. A prospective study of the influence of HIV status on the seroreversion of serological tests for syphilis. Dermatology, 198: 362-9, 1999.

2. Malone, J.L. et al. Syphilis and neurosyphilis in a human immunodeficiency virus type- I seropositive population: evidence for frequent serologic relapse after therapy. Am. J. Med., 99: 55-63, 1995.

3. Seliati,T.J. et al.Virulent Treponema pallidum, lipoprotein, and synthetic lipopeptides induce CCR5 on human monocytes and enhance their susceptibility to infection by human immunodeficiency virus type I.J. Infect. Dis., 181:283-93, 2000.
4. Yinnon, A.M. et al. Serologic response to treatment of syphilis in patients with HIV infection. Arch. Intern. Med., I 56: 321-5, 1996.

1. Médico residente em Patologia Clínica do Hospital das Clínicas da Universidade Federal de Minas Gerais (HC/UFMG). 2. Bioquímica do Setor de Soroimunologia do Laboratório Central do HC/UFMG.

3. Médica patologista clínica; chefe do setor de Soroimunologia do Laboratório Central do HC/UFMG 